\title{
What modes of escape are suitable for evacuees from tsunami disasters? - various levels of infrastructure and population
}

\author{
J. Lee, K. Hatoyama \& H. Ieda \\ Department of Civil Engineering, The University of Tokyo, Japan
}

\begin{abstract}
The Great East Japan Earthquake of March 11 ${ }^{\text {th }}, 2011$ was distinct from the 1995 Kobe earthquake, especially in the causes of deaths. The former was characterized mainly by deaths due to drowning from the tsunami, while the latter was characterized by deaths due to structures that collapsed in the earthquake. The tsunamis also required evacuees to escape distances of over 15km, and the Evacuation Action Plan (EAP) had recommended walking mode as the only official mode of escape. This research focuses on the Tohoku Area from a macroscopic perspective. Data was used from a survey by the Ministry of Land, Infrastructure, Transport and Tourism (MLIT) with 10,601 evacuees at shelters. The Evacuation Assessment Support System (EASY) was formulated using the following parameters: distance to shelters, population density and evacuation speed. Residents living in Fukushima Prefecture did not have the advantage of escaping by walking. Iwate Prefecture had the advantage of car mode, but the EAP does not encourage this.

Keywords: car evacuation, EASY (Evacuation Assistance Support System), tsunami evacuation.
\end{abstract}

\section{Introduction}

\subsection{Background}

A distinctive aspect of the disaster that struck Eastern Japan on March $11^{\text {th }}$ 2011 was that $92.4 \%$ of the casualties were caused by drowning from the tsunami [1, 2], whereas in the Kobe earthquake of 1995, fatalities were caused mainly by structures that collapsed in the ruinous shakes [2, 3]. This 2011 
disaster has been broadcasted worldwide and has awakened us to the tremendous destructive power and threatening impact of tsunamis. The tragic events have gathered much attention and have opened way to research opportunities on topics related to evacuation and risk reduction from earthquakes as well as from tsunamis [4-6]. The central government of Japan, especially the Ministry of Land, Infrastructure, Transport and Tourism (MLIT), has conducted surveys using formulated questionnaires to collect data on the condition of the actual evacuations for a period of six months after the disaster [7]. Using the responses from 10,631 evacuees in the Tohoku area as primary data [8], researchers were able to record data on individual evacuation time, distance, speed, mode share ratio and other general information.

\subsection{Problem statement}

The congestion problems resulting from a simultaneous and sudden increase in the escaping population were analysed in the discrete-space (cellular automatabased or lattice-based [9-12]), route choice in the network, or queuing models $[13,14]$, space continuous as the social force and magnetic force model $[15,16]$. Related researches mainly focused on evacuation behaviours using walking mode. While walking mode is recommended as a mode of escape, car mode is often prohibited in order to give way for emergency vehicles during the emergency action plan [17-19]. However, several practical problems in using walking as the main evacuation mode were enumerated - walking is not always the optimal mode as proven in the case of the Great East Japan Earthquake.

In this disaster, evacuees were required to move both in horizontal and vertical directions for long distances to reach the shelters. They were required to escape not from individual buildings, but from entire cities or towns in order to evade the impending threats. It took around 30 minutes after the earthquake with a magnitude of 9.0 before the tsunamis inundated $600 \mathrm{~km}$ of the eastern coastal line of the Japanese archipelago for as deep as $14 \mathrm{~km}$ into the inland [20]. The emergency tsunami warnings allowed for an evacuation time of about 30 minutes to evacuate $14 \mathrm{~km}$ from their original site, which corresponds to an estimate of $30 \mathrm{~km} / \mathrm{h}$. In this case, the use of car mode can be the optimal evacuation mode or even an exclusive option in special occasions. Even though the Evacuation Action Plan (EAP) strongly recommended walking mode for evacuees [17-19], in reality car mode was generally used according to the survey results in the Tohoku area. The mode ratio was different among the cities. In the case of Yamamoto, 94\% of evacuees used car mode while in cities where casualties were greatest, the mode ratio for cars was lower than the $65 \%$ average: $63 \%$ in Rikuzentakata, 57\% in Otsuchi, 52\% in Onagawa and 52\% in Ishinomaki (52\%) $[7,21,22]$.

These results cannot explain the reasons for the casualties, and the EAP did not have sufficient information to justify mode choices at the time of the evacuation [23]. 


\subsection{Objective}

As abovementioned, evacuation required in the Great East Japan Earthquake was not between two areas in the vicinity, but often across long distances from one city or metropolitan area to another. This research considered the macroscopic point of view because the evacuation distance was comparatively longer and the number of evacuees escaping the tsunami was large. Special focus was given to congestion and car speed, as well as to the walking mode in accordance with the level of infrastructure and population density.

\section{Emergency Action Plans and evacuation behaviours}

\subsection{Evacuation Action Plans}

In the current EAP as well as in the official guidance, individual car mode is prohibited and walking is usually the only accepted mode for evacuation. Some of the reasons stated include the possibility of serious congestion, uncertainty in the road condition, and the need for rapid movement of emergency vehicles [17-19]. The recommendation for keeping the roads open to emergency vehicles is expressed in a succinct phrase: "Do not drive."

\subsection{Characteristics of evacuation}

The results of the survey conducted by $[8,24]$ show that the average mode share ratio for cars was 65\%, and 68\% of evacuees in their 30s used cars for evacuation. Approximately $51 \%$ of car users did not have any problems escaping by driving. The main reasons for delays in escaping among car users (29\%) were broken signals (12.5\%) and traffic jams (11.7\%). The main reason for using car mode was to escape with family (57.6\% in Rias areas, $56.8 \%$ in Plain areas, multi-reply) and the distance of refuge to safe areas (50.4\% Rias in areas, $54.8 \%$ Plain in areas). Given the geographical conditions and the distance to safe areas, many evacuees used cars because they thought that they would not be able to reach safety by foot, and feared being alone. Tables 1-3 show a summary of [8].

\subsubsection{Evacuation Starting Time (EST)}

It was found that bicycle mode was the fastest evacuation mode. Cars, as shown in Table 1, were faster than walking. These differences are related to the preparation time needed for the chosen mode. The median EST of walking mode was 28min, while the tsunami reached shore in approximately 30min. [8, 22]. Thus, about $50 \%$ of evacuees who chose walking mode were at risk. The mode ratio for cars was 94\% in Yamamoto city. Shelters are far from the residential areas and safe areas were scarce in the vicinity because of the city's location in the plain area $[8,20,21]$.

The EST for cars was faster than walking, despite the fact that car mode required additional time for warming up. The results include not only the time for deciding on the choice of mode but also to decide whether evacuees really 
need to take action and escape or not. In fact, 35\% of citizens initially did not think that the tsunami would reach their residential area [8].

The average population density of the Tohoku area is not very high, at an average of $544 \mathrm{p} / \mathrm{km}^{2}$ [22]. Therefore, car mode is preferred if available. In the EST model, an initial value of $5 \mathrm{~min}$ was assumed for walking, $10 \mathrm{~min}$ for bicycle and $15 \mathrm{~min}$ for car.

Table 1: $\quad$ Evacuation Starting Time for each mode (data: [8], 29 cities).

\begin{tabular}{|l|c|c|c|c|c|}
\hline Mode & $25 \%$ & $50 \%$ & $75 \%$ & $95 \%$ & Samples \\
\hline Walking & $13 \mathrm{~min}$. & $28 \mathrm{~min}$. & $47 \mathrm{~min}$. & $98 \mathrm{~min}$. & 6,326 Trips \\
\hline Bicycle & $5 \mathrm{~min}$. & $13 \mathrm{~min}$. & $36 \mathrm{~min}$. & $84 \mathrm{~min}$. & 479 Trips \\
\hline Car & $8 \mathrm{~min}$. & $18 \mathrm{~min}$. & $39 \mathrm{~min}$. & $85 \mathrm{~min}$. & 6,483 Trips \\
\hline
\end{tabular}

\subsubsection{Evacuation Distance to Shelter (EDS):}

The distribution of EDS for each mode is shown in Table 2. More than $50 \%$ of evacuees who used car mode travelled for more than $1,600 \mathrm{~m}$ to find safe areas, while $95 \%$ of evacuees who used walking mode found safe areas within $1,500 \mathrm{~m}$. $50 \%$ of evacuees who chose walking mode moved less than $300 \mathrm{~m}$, while only $5 \%$ of the evacuees within the $250 \mathrm{~m}$ distance moved by car [8]. Based on these results, the maximum evacuation distance for walking mode was derived at $1,500 \mathrm{~m}$.

Table 2: $\quad$ Evacuation distance for each mode (data: [8]).

\begin{tabular}{|l|c|c|c|}
\hline Cumulative Relative Frequency & $\begin{array}{c}\text { Walking } \\
(6,326 \text { trips })\end{array}$ & Bicycle (479 trips) & $\begin{array}{c}\text { Car } \\
(6,483 \text { trips })\end{array}$ \\
\hline $95 \%$ & $1500 \mathrm{~m}$ & $5300 \mathrm{~m}$ & $7600 \mathrm{~m}$ \\
\hline $50 \%$ & $300 \mathrm{~m}$ & $900 \mathrm{~m}$ & $1600 \mathrm{~m}$ \\
\hline $25 \%$ & $200 \mathrm{~m}$ & $500 \mathrm{~m}$ & $800 \mathrm{~m}$ \\
\hline $5 \%$ & $100 \mathrm{~m}$ & $100 \mathrm{~m}$ & $300 \mathrm{~m}$ \\
\hline
\end{tabular}

\subsubsection{Evacuation Speed for Each Mode (ESM):}

Cars were five times faster than walking, as shown in the average ESM in Table 3. However, the cars' average speed of $14.7 \mathrm{~km} / \mathrm{h}$ was slower than the design speed of $60 \mathrm{~km} / \mathrm{h}$. This shows that serious congestions and damaged roads affected the evacuation.

Table 3: $\quad$ Evacuation Speed for Each Mode (data: [8])

\begin{tabular}{|l|c|c|c|}
\hline & Walking & Bicycle & Car \\
\hline Ave. & $2.6 \mathrm{~km} / \mathrm{h}$ & $9.8 \mathrm{~km} / \mathrm{h}$ & $14.7 \mathrm{~km} / \mathrm{h}$ \\
\hline Var./Ave. & 3.6 & 7.6 & 8.7 \\
\hline Max. (Assumption) & $2.6 \mathrm{~km} / \mathrm{h}$ & $9.8 \mathrm{~km} / \mathrm{h}$ & $50 \mathrm{~km} / \mathrm{h}$ \\
\hline Min. (Assumption) & $2.6 \mathrm{~km} / \mathrm{h}$ & $9.8 \mathrm{~km} / \mathrm{h}$ & $2.6 \mathrm{~km} / \mathrm{h}$ \\
\hline
\end{tabular}


The average speeds for walking and bicycle were $2.6 \mathrm{~km} / \mathrm{h}$ and $9.8 \mathrm{~km} / \mathrm{h}$ in the model used. The variation in speed was probably influenced by geographical conditions rather than the population density [26]. So, the maximum and minimum speeds were assumed to have the same value as the average. It was assumed that bicycles followed the same logic. However, different speeds were used for car mode among the various population densities because while geographical conditions do not affect the speed of cars, delays or jamming may be caused based on the population density [26]. Therefore, a speed-density curve as shown in eqn (1) was derived. The population density is $P_{i}$ (Population density $i, p / \mathrm{km}^{2}$ ) and the speed of the car is $v_{P_{i}, C}$ (Car speed, when $P_{i}, v_{P_{i}}, \mathrm{~km} / \mathrm{h}$ ). The curve is defined by three points: minimum speed - population $\left(1000 \mathrm{p} / \mathrm{km}^{2}\right)$, average speed - population $\left(544 \mathrm{p} / \mathrm{km}^{2}\right)$, and maximum speed -population (1 $\left.\mathrm{p} / \mathrm{km}^{2}\right)$.

$$
v_{P_{i}, C}=56.3 e^{-0.003 P_{i}},\left(\mathrm{R}^{2}=0.97, \mathrm{~N}=3\right)
$$

\section{Deriving EASY chart (Evacuation Assessment Support System)}

\subsection{Effective parameters}

Focus was given to the macroscopic effects that traffic congestions have on evacuation. The first parameter is population density $\left(\mathrm{p} / \mathrm{km}^{2}\right)$, combined with the population and area in each region. The population covers various aspects such as the complex community groups in high density areas or the fact that areas with lower population density have smaller financial support from the government, which lead to various disadvantages (e.g. insufficient infrastructure, lack of alternative roads). Although population density cannot explain everything, it is a useful parameter to explain various characteristics of a given society.

The second parameter is distance to shelters (average distance to official refuge). Evacuation speed, time, and distance can be considered intuitively, but the speed and time may vary and may also be difficult to measure. The average distance to shelters was used to calculate the number of refuges divided by the area.

\subsection{The best distance and maximum distance to escape using walking mode in CAM (Comparative Advantage Modes)}

The evacuee can reach a shelter without much effort when it is close from the original location, but it would be impossible if the shelter is too far away. In this section, time-space diagrams are derived to define the CAM, along with the best distance and maximum distance for walking mode. Line $C$ (eqn (2)) is the walking distance under the conditional time, while line $B$ (eqn (3)) is for the bicycle mode in Fig. 1. In EST (section 2.2.1), $t_{W}$ (evacuation starting time for 
walking mode) is calculated at 5 min., $t_{B}$ (evacuation starting time for bicycle mode) at $10 \mathrm{~min}, t_{C}$ (evacuation starting time for car mode ) at $15 \mathrm{~min}$.

$$
C\left(t_{i}\right)=\left\{\begin{array}{cc}
0, & t_{i} \leq t_{w} \\
v_{w}\left(t_{i}-t_{w}\right), & t_{\max } \geq t_{i}>t_{w}, \\
d_{\max }, & t_{\max }<t_{i}
\end{array} \quad \text { for } 0<i<\infty\right.
$$

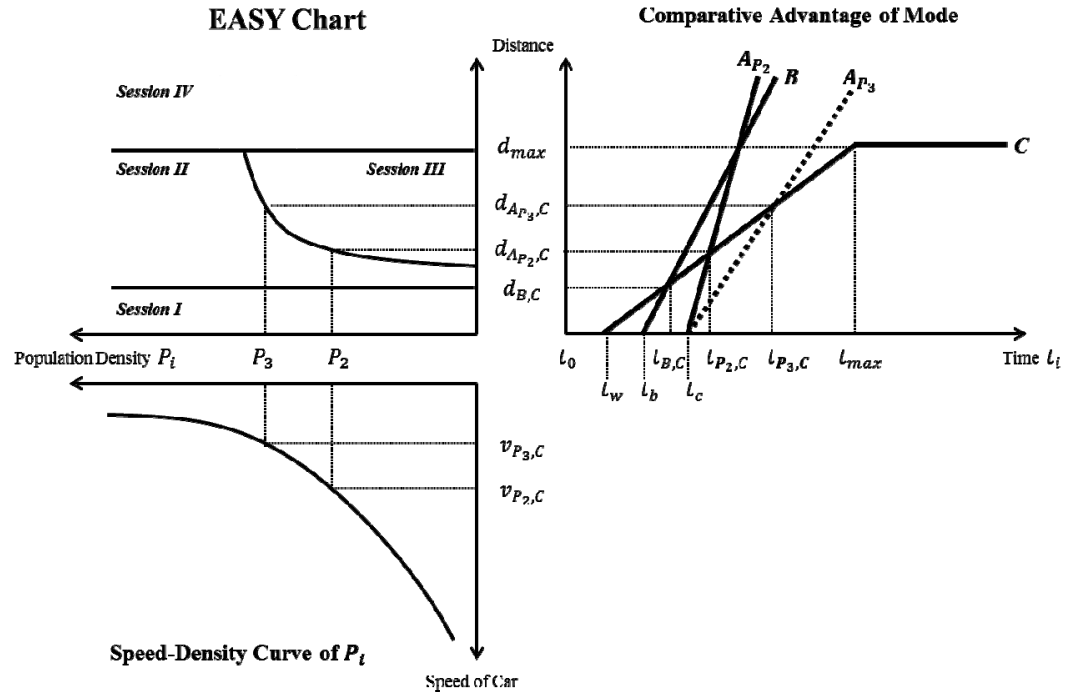

Figure 1: $\quad$ Concept of the EASY chart.

$$
B\left(t_{i}\right)=\left\{\begin{array}{cc}
0, & t_{i} \leq t_{b} \\
v_{b}\left(t_{i}-t_{b}\right), & t_{i}>t_{b}
\end{array} \quad \text { for } 0<i<\infty\right.
$$

When the crossing distance between line $B$ and $C$ is $d_{B, C}$ (eqn (4)), CAM shifts from $C$ to $B$ at time, $t_{B, C}$. If the distance to the shelter is shorter than $d_{B, C}$, evacuees can reach this distance by walking mode at $t_{B, C}$ because $50 \%$ of evacuees using walking mode were able to begin evacuating at time $t_{W}$. While bicycle mode is faster than walking mode, evacuees using bicycle mode were only able to begin evacuating at time $t_{B}$.

$$
d_{B, C}=C\left(t_{B, C}\right)=B\left(t_{B, C}\right), \quad \text { for } t_{B}<t_{B, C}<t_{\max }
$$

The maximum EDS, $d_{\max }$, for walking in the previous section 2.2.2 was derived based on the walking distance for the $5 \%$ of evacuees who walked more than $1,500 \mathrm{~m}$. However, $t_{B, C}$ is out of boundary from $t_{B}$ to $t_{\max }$, and $d_{B, C}$ cannot be derived because $t_{B, C}$ is not defined. In this case, eqn (5) can be used instead of eqn (4). 


$$
d_{\text {max }}=\left\{\begin{array}{cc}
0, & t_{B, C} \leq t_{w} \\
v_{w}\left(t_{B, C}-t_{w}\right), & t_{B, C}>t_{w}
\end{array}\right.
$$

Eqns (4), (5) include the maximum evacuation time (MET), or how much time evacuees can use for evacuation.

\subsection{Comparative Advantage between Waking and Car Mode}

Line $A_{P_{i}}$ (eqn (6)) is the moving distance for car mode when the population density is $P_{i}$, the speed is $v_{P_{i}, C}$, within $t_{i}>t_{c}$. The speed of the car, $v_{P_{i}, C}$, is calculated by eqn (1); $v_{P_{i}, C}$ has various values for different $P_{i}$. The speed decreases when $P_{i}$ increases in eqn (1).

$$
A_{P_{i}}\left(t_{i}\right)=\left\{\begin{array}{cl}
0, & t_{i} \leq t_{c} \\
v_{P_{i}, C}\left(t_{i}-t_{C}\right), & t_{i}>t_{c}
\end{array} \quad \text { for } 0<i<\infty\right.
$$

When the distance to the shelter is $d_{A_{P_{i}},}$, (eqn (7)), CAM shifts from C to $A_{P_{i}}$ at population density, $P_{i}$. When the distance to the shelter is more than $d_{A_{P_{i}}, C}$, car mode is faster than walking mode at population density $P_{i}$.

$$
d_{A_{P_{i}}, C}=C\left(t_{P_{i}, C}\right)=A_{P_{i}}\left(t_{P_{i}, C}\right), \quad \text { for } t_{C}<t_{P_{i}, C}<t_{\max }
$$

CAM between $A_{P_{i}}$ and $B$ is not the only crossing point because for each population density $P_{i}$, the speed for car mode differs, while $d_{B, C}$ has one crossing point. However, if $t_{B, C}$ is out of boundary from $t_{c}$ to $t_{\text {max }}$, then eqn (8) and $d_{A_{P_{i}}, C}$ can be affected by MET.

$$
d_{A_{P_{i}}, C}=d_{B, C}
$$

Further, three types of distances are defined.

The first is $d_{B, C}$. Walking mode has an advantage at distances of less than $d_{B, C}$, while at distances of more than $d_{B, C}$, bicycle or car mode have an advantage. However, because $t_{\max }$ is very short, evacuees cannot reach the shelter even if they can walk more than $1,500 \mathrm{~m}$. If assumptions are made for EST and ESM $\left(t_{w}=5 \mathrm{~min}, t_{b}=10 \mathrm{~min}, v_{w}=2.6 \mathrm{~km} / \mathrm{h}, v_{b}=9.8 \mathrm{~km} / \mathrm{h}\right.$ shown in section 2.2.1-3), $t_{B, C}$ is $11.8 \mathrm{~min}$ and $d_{B, C}$ is $295 \mathrm{~m}$. Considering these parameters, walking mode has an advantage at distances that are less than $295 \mathrm{~m}$.

The second type of distance is $d_{\max }$, which satisfies the boundary condition $\left(t_{B}<t_{B, C}<t_{\max }\right)$, and $d_{\max }$ is $1,500 \mathrm{~m}$.

The third type of distance is $d_{A_{P_{i}}, C}$. When the population density is fixed at $P_{i}=500 \mathrm{p} / \mathrm{km}^{2}$ and EST at $t_{C}=15 \mathrm{~min}$ as shown in section 2.2.1, then $v_{500, C}$ is 12.6 $\mathrm{km} / \mathrm{h}, t_{500, C}$ is $17.8 \mathrm{~min}$ and $d_{A_{500}, C}$ is $546.4 \mathrm{~m}$. 


\subsection{Positioning of sessions in EASY chart}

The division line between Sessions I and II is $P_{i}=d_{B, C}$ as shown in Fig. 1, and has the same CAM for walking and bicycle mode. If the distance is less than distance $d_{B, C}$, evacuees can reach the shelter in the shortest time. Constant speeds are assumed for walking and bicycle mode, so CAM is not largely different for various $P_{i}$. The division line between session II and III is $P_{i}=$ $d_{A_{P_{i}}, C}$, which is the set of $d_{A_{P_{i}}, C}$ along the various $P_{i}$. Each element has the same CAM for walking and car mode to reach distance $d_{A_{P_{i}}, c}$. For car mode, it was assumed that higher population density causes slower car speed. The division line for Session VI is $P_{i}=d_{\max }$ for $0<i<\infty$, which shows the maximum distance in walking mode according to the smaller of the following: $95 \%$ of the walking distance for evacuees and the walkable distance inundation by the tsunami. For distances of more than $d_{\max }$, car mode does not always have a CAM, but there are no options other than car mode.

\section{EASY chart in population density and distance field}

\subsection{Session I (best for walking mode)}

Walking mode has the greatest CAM for the first $295 m$ (as shown in Fig. 1). If the evacuation distance is less than $295 \mathrm{~m}$, fewer people use car mode. Less than $5 \%$ of the evacuees used car mode (as shown in Table 2). In Session I, walking was the primary mode of escape regardless of population density. If the population density is very low, evacuees can choose any mode because of minimal congestion.

\subsection{Session II (car mode could be prohibited)}

Walking mode is a CAM over car mode. If evacuees use car mode, serious congestion could be expected due to the high population density. Furthermore, the distance to shelters is shorter than $1,500 \mathrm{~m}$, and thus is walkable. In this case, it is recommended that evacuees walk instead of drive to evade road congestions and give way for emergency vehicles.

\subsection{Session III (car mode may be recommended)}

Car mode is the CAM. This session contains lower population density and the distance to shelters is less than $1,500 \mathrm{~m}$. The number of cars is not high, and thus congestion would not adversely limit driving speed. Thus, this area could allow evacuees to freely choose their preferred evacuation mode. Additionally, it is important to take into consideration the safety of evacuation routes to high altitudes in order to survive tsunamis. 


\subsection{Session IV (dangerous, needed more facilities)}

Many problems are cited for Session IV. It may be difficult to reach shelters by foot, and thus evacuees might consider the use of car mode. However, road conditions may not guarantee safety after a strong earthquake, and the high population density may cause serious traffic congestions. It is strongly recommended that provisions would be implemented for more facilities and infrastructure that could serve as temporal refuge areas.

\section{Comparison and application}

Each city in the Tohoku area is located in the EASY chart based on population density and the average distance to shelters; Session 1: Rifu, Session 2: Natori, Matsuchima, Session 3: Iwanuma, Watari, Iwaki, Minamisoma, Ishinomaki, Minamisanriku, Kamaishi, Yamamoto, Shinchi, Session 4: Soma, Rikuzentakata, Ofunato, Kuji, Otuchi, Noda, Yamada, Tanohata, Miyako, Onagawa, Misawa, Kesennuma, and the characteristics of each session are shown in Table 4. For example, in the case of Session 1, shelters are closer than 295m. Only one city (Rifu) belongs to this session, so the other sessions II-IV will be compared in this section.

\subsection{Evacuation Speed and Distance}

There is not much difference in Evacuation Speed among the various walking modes. In car mode, Session II $(9.3 \mathrm{~km} / \mathrm{h})$ is slower than others in Evacuation speed. Session III (63\%) has a bigger mode share for cars than Session II (57\%). This implies that fewer evacuees used cars because of the low speed of car mode due to factors such as congestion. This can be supported by the survey answers such as "Problems to access the shelters" and "Reason not to go to the nearest shelter". Session II shows the highest proportion of "Overcapacity in accessing the shelters (65\%)" and "Found easy place because evacuees can not to go to the nearest shelter (59\%)". Session III shows that the car mode is a CAM, and Session IV does not have options other than car mode. Evacuees in these sessions felt that that distance was a problem in accessing shelters by car mode, and thus answers such as "Reasons for Car use" and "Problems to access the shelters" are seen. Session III and IV show a high proportion of answers that note "Lack of Time and Long Distance (78\%, 70\%)" and "Long Distance and Difficult Accessibility (69\%, 66\%)". However the mode share ratios are different between Session III (car: 64\%) and IV (walking: 55\%). This shows that there is a great advantage in using car mode in Session III because evacuees can move longer distances (Evacuation distance: 2,402m) at the fastest speed of cars (Evacuation Speed: $13.1 \mathrm{~km} / \mathrm{h}$ ) at the lowest congestion (Serious congestion: 9\%). Additionally, Sessions II and IV show serious congestion (II: 22\%, IV: $39 \%$ ) that is significantly larger than Session III's (9\%).

Finally, if the mode share ratio of cars increases, Session II faces more serious congestion problems (Overcapacity; 65\%, serious congestion: 22\%). The 
highest proportion of car mode (63\%) was seen in Session III, but at the same time, this session was characterized by the highest speed of cars $(13.1 \mathrm{~km} / \mathrm{h})$, the longest distance travelled $(2,402 \mathrm{~m})$ and least congestion (9\%). Session IV had the smallest proportion of evacuees in car mode (only 43\%), and was characterized by long distances to shelters (39\%) and most serious congestion (39\%). Further, the evacuation distance on foot (309m) was longer than Session III $(255 \mathrm{~m})$. In the case of Session I, evacuees wanted to use car mode for "keeping asset (23\%)" and "escaping with family (57\%)". Evacuees in Session I had the flexibility to choose their evacuation mode because of the shorter evacuation distance (walking: 144m, car: 490m) and the highest portion for car mode (78\%).

Table 4: $\quad$ Results of averages of each session.

\begin{tabular}{|c|c|c|c|c|c|}
\hline \multicolumn{2}{|r|}{ Content } & $\mathrm{I}$ & II & III & IV \\
\hline \multirow{3}{*}{$\begin{array}{l}\text { Evacuation } \\
\text { Speed(km/h) }\end{array}$} & Walking & 1.7 & 3.3 & 2.8 & 2.8 \\
\hline & Bicycle & N/A & 4.5 & 10.4 & 8.1 \\
\hline & Car & 3.8 & 9.3 & 13.1 & 12.1 \\
\hline \multirow{3}{*}{$\begin{array}{l}\text { Evacuation } \\
\text { Distance(m) }\end{array}$} & Walking & 144 & 441 & 255 & 309 \\
\hline & Bicycle & N/A & 600 & 1,373 & 764 \\
\hline & Car & 490 & 2,435 & 2,402 & 1,287 \\
\hline \multirow{3}{*}{$\begin{array}{l}\text { Mode Share } \\
\text { Ratio (\%) }\end{array}$} & Walking & 22 & 35 & 34 & 55 \\
\hline & Bicycle & 0 & 8 & 3 & 2 \\
\hline & Car & 78 & 57 & 63 & 43 \\
\hline \multirow{4}{*}{$\begin{array}{l}\text { Reasons of } \\
\text { Car use (\%) }\end{array}$} & Lack of Time and Long Distance & 69 & 66 & 78 & 70 \\
\hline & Escaping with Family & 9 & 14 & 10 & 19 \\
\hline & Keeping Asset & 23 & 20 & 12 & 11 \\
\hline & Total & 100 & 100 & 100 & 100 \\
\hline \multirow{4}{*}{$\begin{array}{l}\text { Problems to } \\
\text { access the } \\
\text { shelters (\%) }\end{array}$} & Long Distance & 25 & 13 & 31 & 39 \\
\hline & Difficult Accessibility & 50 & 23 & 38 & 27 \\
\hline & Overcapacity & 25 & 65 & 32 & 34 \\
\hline & Total & 100 & 100 & 100 & 100 \\
\hline \multirow{5}{*}{$\begin{array}{l}\text { Reasons not } \\
\text { to go to the } \\
\text { nearest } \\
\text { shelter (\%) }\end{array}$} & Serious Congestion & - & 22 & 9 & 39 \\
\hline & Escaping with Family & 57 & 18 & 21 & 21 \\
\hline & Found Easy Place & 43 & 59 & 65 & 37 \\
\hline & Long Distance & - & 2 & 5 & 3 \\
\hline & Total & 100 & 100 & 100 & 100 \\
\hline Sample & Trips & 36 & 518 & 5,269 & 6,575 \\
\hline
\end{tabular}

\section{Conclusion}

The results of the surveys show that the mode ratio for cars was over $50 \%$ higher in some regions as compared to other regions. Key concepts used for the comparison include: speed variation based on the population density, evacuation distance, and evacuation starting time of each mode. The geographical condition can be one of the important effective parameters, but this is not included in this model. 
In this research, an attempt was made to formulate a general guidance for evacuation based on the given conditions of refuge and population density, as well as the traffic mode and travel distance. A general recommendation can be made for refuge plans and the preferred mode of escape. Using the EASY chart, the characteristics of evacuation in various cities were compared. This can serve as a useful means to understand the given condition of infrastructure as well as the tendencies and travel behaviours at a macroscopic level.

From a macroscopic point of view, high population density and long evacuation distance lead to serious congestion. If the evacuation distance is too long, evacuees could fail to escape from the hazardous areas. In this study, the researchers derived the EASY chart to compare the different conditions of facilities and population, categorized into four sessions.

Sessions I and II do not benefit from using car mode for evacuation. It is therefore recommended to identify the shortest pedestrian route for easy evacuation. Strategies to reduce the mode ratio for car use are necessary in Session II. In Session IV, serious congestion could result from the high population density, and none of the enumerated modes are able to provide full security and assurance. Therefore, it is recommended that provisions are implemented for temporal refuges and shelters. Although there are no alternatives besides car mode and this mode does not guarantee safety, the use of car mode should not be prohibited. In Session III, the mode ratio for cars was higher than others, congestions were limited and high driving speeds were reported. Therefore, this session has the largest advantage of using car mode among all sessions. The design of the evacuation route in session III should always take into consideration the safest route (e.g. higher roads) as well as the shortest path from the possible tsunami in order to accommodate for the long distance of travel.

\section{References}

[1] National Police Agency (NPA), www.npa.go.jp

[2] Metropolitan Police Department (MPD), www.keishicho.metro.tokyo.jp

[3] Digital Japan Portal Web Site (DJPW), http://portal.cyberjapan.jp

[4] Wegscheider, S., Post, J., Mück, M., Zosseder, K., Muhari, A. \& Anwar, H.Z., Generating tsunami risk knowledge at community level as a base for planning and implementation of risk reduction strategies, Nat. Hazards Earth Syst. Sci., 11, pp. 249-258, 2011.

[5] T. Charnkol \& Y. Tanaboriboon, Tsunami Evacuation Behavior Analysis one step of transportation disaster response - IATSS Research Vol. 30 No. 2, 2006.

[6] Limanond, T., Kim, H., Siridhara, S., Tipakornkiat, C., Chermkhunthod, C. and Uttra, S., Decision on Tsunami Evacuation Route in Tourism Area: A Case Study of Had Patong, Phuket, Journal of the Eastern Asia Society for Transportation Studies 9(0), pp. 16-30, 2011.

[7] MLIT (Ministry of Land Infrastructure, Transport and Tourism), www.mlit.go.jp 
[8] ARSI (Archive of Reconstruction Supporting Investigation), http://fukkou.csis.u-tokyo.ac.jp

[9] Blue, V. J. and Adler, J. L., Cellular Automata Microsimulation for Modeling bi-directional Pedestrian Walkways, Transportation Research B 35, pp. 293-312, 2001.

[10] Burstedde, C., Klauck, K., Schadschneider, A. and Zittartz, J., Simulation of pedestrian dynamics using a two-dimensional cellular automaton, Volume 295, Issues 3-4, pp. 507-525, 2001.

[11] Nagel, K., From Particle Hopping Models to Traffic Flow Theory, Journal of the Transportation Research Board, Volume 1644, pp. 1-9, 1998.

[12] Schadschneider, A., Cellular Automaton Approach to Pedestrian Dynamics - Theory Pedestrian and Evacuation Dynamics, M. Schreckenberg and S.D. Sharma (Eds.), p. 75 (Springer 2001).

[13] Løvås, G. G., Modeling and simulation of pedestrian traffic flow, Volume 28, Issue 6, pp. 429-443, 1994.

[14] Yuhaski S. J. and Smith, J. M., Modeling circulation systems in buildings using state dependent queueing models, Queueing Systems, Volume 4, Issue 4, pp. 319-338, 1989.

[15] Helbing, D., Molnár, P., Social force model for pedestrian dynamics, Phys. Rev. E 51, pp. 4282-4286, 1995.

[16] Okazaki, S., A Study of Pedestrian Movement in Architectural Space, Part 1: Pedestrian Movement by the Application on of Magnetic Models, Trans. of A.I.J., No.283, pp.111-119, 1979.

[17] DPI (Disaster Prevention Information), www.bousai.metro.tokyo.jp

[18] FEMA (Federal Emergency Management Agency), www.fema.gov

[19] NEMA (National Emergency Management Agency), www.nema.go.kr

[20] JMA (Japan Meteorological Agency), www.jma.go.jp

[21] Geospatial Information Authority of Japan (GIA), www.gsi.go.jp

[22] Statistics Bureau, Director-General for Policy Planning and Statically Research and Training Institute (SBDG), www.stat.go.jp

[23] Lee, J., Park, S., Macroscopic View of Tsunami Damages and Evacuation Behaviours - The 3.11 Earthquake in Tohoku, Japan-, Proc. Of the $67^{\text {th }}$ Int. Conf. on Korea Society of Transportation, 2012, in Korean.

[24] Ministry of Land, Infrastructure, Transport and Tourism (MLIT), Survey Report of Reconstructing Method for Damaged City by Tsunami Disaster, 2012, in Japanese, www.mlit.go.jp/common/000209868.pdf

[25] Hoogendoorn, S. P., Pedestrian Behavior at Bottlenecks, Transportation Science, vol. 39 no. 2, pp. 147-159, 2005.

[26] Lee, J., Heo, M., Park, I. and Chung, J., The Rotated Hexagonal Lattice Model for Pedestrian Flows, Proceedings of the Eastern Asia Society for Transportation Studies, Vol. 7, 2009. 